\title{
TRAUMA-INFORMED OUT-OF-HOME CARE
}

\author{
Scott Hanauer \\ Community Youth Services, Olympia, WA
}

Many children in the child welfare system who live in out-of-home care have histories of complex or recurrent trauma. Children who have experienced complex trauma have significantly higher rates of internalizing problems, posttraumatic stress, anxiety, and externalizing behavior problems. This is certainly true in the Therapeutic Foster Care Program at Community Youth Services (CYS). The children who are referred to CYS's therapeutic foster care program have had multiple out-of-home placements. On average, youth who were referred to CYS's therapeutic foster care program have been in nine previous placements including foster homes, residential treatment programs, extended families, or in-patient hospitals. A significant amount of research exists related to how trauma negatively impacts behavior, emotional development, academic progress, the development of coping skills, and even neurology. Less information is available to caregivers regarding strategies to help children mitigate the impact of trauma, especially toward decreasing problem behaviors or in helping children develop self-regulation skills.

CYS's therapeutic foster care program was intended to serve the most vulnerable children in Washington State's foster care system. These children are defined as needing behavioral rehabilitative services (BRS) foster care due to the challenges they experience in many areas of their lives, including school, home and family, the juvenile justice system, and mental health services. Washington State Children's Administration defines BRS as a "temporary intensive wraparound support and treatment program for youth with extreme, high-level service needs used to safely stabilize youth and assist in achieving a permanent plan or less intensive services." BRS can be provided in residential treatment facilities, foster care homes, and family homes.

In 2009, an intensive effort was made at CYS to identify key factors that supported improved outcomes for youth who qualified for BRS services. Placement stability was determined to be a critical factor, and it was hypothesized that increased placement stability would be essential to improving outcomes in education, namely, academic improvements and behavioral stability, improved mental health, as measured by the Child Functional Assessment Rating Scale, fewer critical incidents, and improved behavior. Another hypothesis was that devoting more resources and support to caregivers would be crucial to improving placement stability. In essence, if caregivers felt supported and were given practical skills to improve placement stability, the youth in their care would do better in many of their life domains.

The Child Functional Assessment Rating Scale (CFARS) is used to measure youths' progress in a number of domains including depression, hyperactivity, cog- 
nitive performance, traumatic stress, interpersonal relationships, danger to self or others, anxiety, thought processes, substance abuse, and behavior problems at school or home. Youth who were discharged from CYS's BRS program between July 2011 and June 2013 demonstrated improvements that ranged from 80\% to $100 \%$ in the domains measured by CFARS. CYS also tracks placement stability, which is defined as the number of placements that are not disrupted by running away, behavior problems, incarceration, caregiver dissatisfaction, or moves to more restrictive settings. Youth moving into permanent placements or returning home are not considered disrupted placements. The placement stability rate for youth discharged from CYS's BRS services between July 2011 and June 2013 was 92.8\%.

CYS staff and caregivers identified a number of areas where they believe improved support would lead to better outcomes. Enhanced behavior management was identified as the most-needed support by caregivers. Many placement disruptions occur because caregivers feel they do not have the skills to deter crisis level behavior.

CYS's staff and foster parents identified a number of skills that have helped youth stabilize and develop improved self-regulation. Caregivers and staff are trained in each of these principles. Caregivers receive home, community, and school-based support and coaching to enhance utilization of the following principles:

- Trauma-informed Adults

- Authoritative Parenting and Engagement

- Understanding the "Test"

- Understanding Self- and Emotional Regulation

- Therapeutic Environments

- Open Environments

- Accountability

- Targeting Sequences of Behavior

- Listening

- Monitoring vs. Supervising

- Collaborating with Schools

- Enhancing Prosocial Activities, Prosocial Peer Relationships, and Prosocial Adult Relationships 


\section{Trauma-Informed Adults}

Many of the communities in which CYS provides therapeutic foster care have been identified as having high incidents of children and families who have experienced adverse childhood experiences (ACES) (Lobnghi, 2012). Adverse childhood experiences include the following: physical abuse, physical and emotional neglect, domestic violence, familial substance abuse, familial untreated mental illness, sexual abuse, and placement disruptions. Research by the Washington State Family Policy Council demonstrates that ACES can lead to lifelong challenges:

- chronic health problems

- mental health problems

- posttraumatic stress disorder

- substance abuse

- tobacco use

- violence and aggression that lower lifetime productivity

- decreased ability to read social skills and develop supportive relationships

- poor emotional regulation

- isolation

- slower language development and speech delays

- poor verbal and memory recall

- lower cognitive functioning (Lobnghi, 2012)

CYS caregivers are provided training in home case management support and consultation to enhance their understanding of how complex trauma impacts youth. Caregivers' understanding of trauma has been important in achieving behavioral and placement stability. Parents, staff, and families of foster youth are supported in understanding the concepts and skills discussed below.

\section{Authoritative Parenting and Engagement}

Authoritative parenting is a child-centered approach in which caregivers have the ability to equally balance acceptance, nurturing, and enrichment with limits, boundaries, and structure. It is important that each caregiver provide these balanced core competencies. It is likely that parents will be polarized if one parent takes on the role of the nurturer and the other takes on the role of the disciplinarian. 


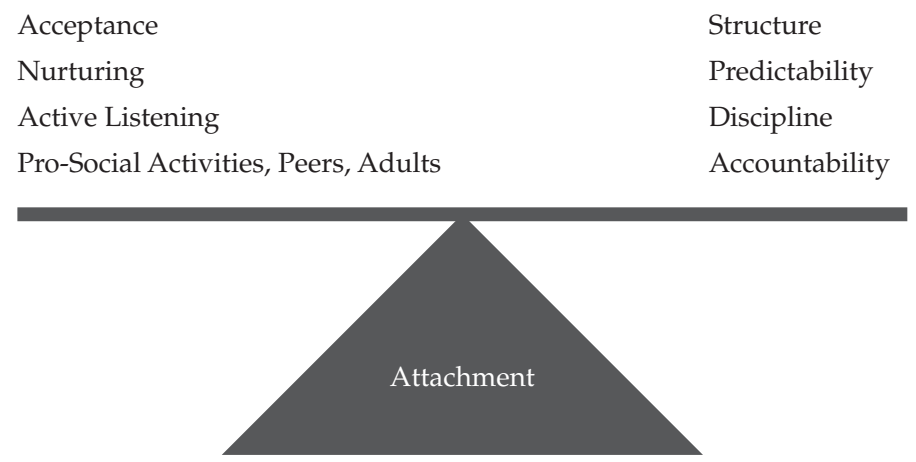

Figure 1

Inherent in authoritative parenting is engagement. Engagement between youth and their caregivers is critical to youth's placement stability as well as to their success in other domains of their lives. Engagement can be difficult to achieve with youth who have histories of being rejected and who have lived in as many as nine or more placements before coming to CYS. Enhancing engagement in out-of home care is particularly challenging for adolescents who demand independence and who are regularly striving to differentiate themselves from adults.

Caregivers and staff are encouraged to understand and employ the following core competencies of engagement:

- Compassion is the caregiver's ability to communicate an appreciative understanding of what it might feel like to feel down, worried, rejected, angry, depressed, or anxious even if the caregiver has not shared the same experiences as the youth in their care.

- Interpersonal warmth and emotional acceptance are critical to the development of attachment. Research demonstrates that when brains detect a positive emotionally charged event, like warmth and acceptance, dopamine is released into a physiological system. Dopamine improves one's memory, information processing, and sense of well-being (Medina, 2014).

Key to authoritative parenting is the ability for caregivers to provide virtually unconditional acceptance to the youth in their care. People will go to great lengths to achieve acceptance. If youth do not find acceptance with their families (birth, extended, foster, adoptive, or chosen) they will find it somewhere else. Many gang affiliated youth and adults acknowledge that they joined gangs for acceptance, not because they wanted to get into trouble. Unfortunately, acceptance into gangs is often measured by the pledge of a new member to commit crimes or hurt others. 
Foster parents are supported in understanding that providing acceptance takes time and is not reciprocated right away. Youth sometimes make it difficult for adults to bond or provide unconditional acceptance. It is often the case that youth will push away from adults who try to get emotionally close too fast. A foster parent once stated that providing acceptance is a bit like hugging a porcupine ... the closer one gets the more likely one is going to get hurt. It is also important to note that acceptance of the youth as a person does not mean that adults have to tolerate that youth's negative behavior.

Research demonstrates that positive attachment and acceptance can positively impact one's brain functioning. "When children are attaching in positive settings, they are literally being wired to become positive people" (Gray, 2007).

Authoritative caregivers and staff must communicate high expectations for the youth in their care. Most youth have had previous experiences where caregivers lowered expectations or ignored minor behavior problems. Lower expectations often elicit escalated behavior. Youth's behavior will continue to escalate, in part, to determine when and how adults will set clear limits.

It is CYS staff's experience that youth who have authoritative caregivers feel safe, are able to more quickly learn self-regulation skills, develop improved social skills, develop better judgment, and become more confident with independence and autonomy.

\section{Understanding the "Test"}

Predictably, youth who are referred to CYS's therapeutic foster care program are frequently mistrustful, cautious, and sometimes expecting to disrupt their newest placement. A 14-year-old girl, who lived in more than 15 foster homes and 2 adoptive homes, once stated, "The only thing worse than being kicked out is in not knowing when rejection will happen ... so I'm going to make it happen."She actually flooded the home of her newest placement by bringing a hose into the house in the middle of the night, turning on the outside spigot and going back to bed. She demanded that her foster family "give up." The foster family was able to maintain her placement, and she went on to graduate from high school and acquired a nursing credential. She continues to have a good relationship with her family and even changed her name to theirs.

Foster families receive support in understanding the meaning of the "test": "Will you replicate what happened to me before?" The test is common with youth who have histories of multiple placements and is especially arduous for youth whose goal is to return to their birth or extended families. The test includes the following:

- Am I safe?

- Are you stable? 
- Will you leave or reject me?

- Can I make you leave me or reject me?

- Can I make you angry, frustrated, emotional, or abusive?

- What will you do when you become angry, frustrated, or emotional?

- How will my life change when I live with you?

The test from young people can range from small power struggles to oppositional or defiant behavior to very serious behavior, like physical aggression, running away, or damaging a house, to making false allegations about the adults in their lives.

Passing the test happens over time, sometimes a very long time, by caregivers being authoritative and communicating the following messages:

- I will remain calm and self-regulated in crises.

- I am in control of my emotions, and I will try to help you control yours.

- I will not destabilize your life again.

- I will give you time to trust me.

- I will try to understand your experiences and your feelings.

- I will say what I mean and mean what I say.

\section{Understanding Self- and Emotional Regulation}

Research and the experience of CYS staff have shown that many youth referred for therapeutic foster care struggle with self-regulation and emotion regulation. Emotional dysregulation can be variable and is expressed in myriad ways, including but certainly not limited to hypervigilance; excessive worry and anxiety; externalizing behavior (physical and verbal aggression, running away, property destruction, threats, self-hurtful gestures, etc.); and poor judgment. Dysregulation also stimulates the physiological releases of adrenaline and cortisol. If untreated, high levels of adrenaline can scar blood vessels and may cause heart attacks and strokes. High levels of cortisol damage the cells of the brain's hippocampus, harming one's ability to learn and remember (Medina, 2014).

Caregivers are supported in understanding strategies to help youth learn selfregulation. The most critical caregiver skill is demonstrating an ability to be calm and self-regulated, especially when dealing with escalated behavior. It is rarely helpful for adults to match the youth's escalated behavior with their own intense demeanor. CYS staff have observed that adults who can demonstrate calmness and self-regulation can positively impact youths' neurology. Mirror neurons are in the emotional centers of the brain, allowing children to feel some of the feelings of staff members when they are tracking them. It is the experience of CYS staff that 
youth will behaviorally and neurologically mirror calm environments and composed adults.

It is important that adults can assess their own triggers for dysregluation. Everyone has emotional buttons that, when pushed, elicit anger, frustration, or exasperation. Youth who have experienced trauma can sense when adults become emotionally tipped over or dysregulated. Youth can sometimes use that personal knowledge to keep pushing caregivers' emotional triggers. Triggers are unique to each adult and can include such things as frequent power struggles, lack of respect, oppositional and argumentative behavior, lack of appreciation, giving up quickly on tasks, and harming pets. Foster parents are asked about deal breakers for keeping a youth in their home instead of asking for a placement change. It is important that adults are not only aware of their personal deal breakers but also the behaviors that prompt them to be emotionally tipped over.

\section{Therapeutic Environments}

Therapeutic environments are as important to youth as their connection to selfregulated caregivers. Youth tend to stabilize, feel safer, and function better when many of the following competencies are in place at home. Predictability, routines, and consistency offer youth a sense of positive power and control in their lives, helping them know what to expect in their homes and when changes will occur. Predictability is as important to youth who have experienced trauma as it is for children who are much younger. For example, toddlers developmentally rely on knowing the routines of their family and home. They frequently react negatively to even small changes in their routines. The same is true for youth who have had traumatic experiences in life.

The experience of staff at CYS have shown that organization helps youth stabilize. Organized homes can help youth improve time management, impulse control, and ability to plan for the future. These critical thinking skills promote enhanced reasoning and an improved ability to listen to the opinions of others.

"If it's broke, fix it!" It is common for youth who have experienced complex traumas to have a trail of chaos in their wake. They bump into others, they accidentally break things, they make messes in their environments, and they knock things over. Caregivers find it particularly frustrating when their youth believe they know how things work when, in fact, they break things like televisions, cell phones, and computers. It is also common for youth to take out their feelings of frustration and anger on walls, doors, furniture, and their own or others' possessions. CYS staff have observed a direct correlation between unrepaired homes and more damage. For example, little holes in the sheetrock become gaping holes, and little bits of graffiti become even more inappropriate images on the walls. Conversely, damage that gets repaired lessens further destruction. Youth have a right to live in an environment that is respected and cared for, but they should be held accountable for the damage they cause. 


\section{Understanding Power and Power Struggles}

Escalated behavior often begins with a power struggle. Tantrums, running away, and verbal or physical aggression often start with youth arguing or making demands that engage their caregivers into power struggles. Understanding the etiology of power struggles and utilizing anticipatory strategies to deter power struggles have proven to be very effective.

Ask typical children what they want to be when they grow up and their answers are almost always the same. They want to be firefighters, police officers, athletes, doctors, soldiers, teachers, their parents, etc. All of those professions have a number of characteristics in common. They are heroes, they are respected, they have power, and they have control. Children will regularly identify with power and control whether those aspirations represent positive role models or negative role models.

Children who grow experiencing trauma may have a much different concept of power and control. Their model of power and control may be someone who abuses others, someone who projects the responsibility for their offensive behavior onto others, including their victims, somebody who minimizes their negative behavior, or someone who threatens others to get their way. Youth who have experienced trauma sometimes use negative behavior to test the strength, resolve, and authority of their caregivers. They may do so because this is how their heroes (perpetrators of their own trauma) garnered power and control by frequently and intensely provoking others to see how they react.

"Power struggles with parents and adults in authority are a normal part of adolescent development because it is during this time of life that young people are beginning to express independence and autonomy" (Whitlock \& Purington, 2013).

Parents who try to avoid power struggles actually find themselves in more power struggles with the youth in their care. Managing power struggles has two fundamental strategies.

The first strategy is offering youth as many choices and as much independence and autonomy as safely possible. It is difficult to get into power struggles with people who give others appropriate control over their lives. Even more important is that people like, and want to bond with, people who give them choices in their lives. Anyone can relate to those who work for a supervisor who gives employees reasonable control over their work as opposed to bosses who micromanage employees.

Offering youth many choices is directly related to decreased power struggle behavior. It is important to offer choices that are acceptable with the adults. Choices that, no matter what choice the youth makes, should not negatively impact anyone else. Parents who understand the importance of independence and autonomy are extremely creative in how they offer choices: "You can wear the blue socks or the brown socks," "You can wear one blue sock and one brown sock," "You can 
have juice or milk," "You can have a half or a full glass of milk," "You can go to bed at nine or nine-fifteen," and so forth. Although those choices seem trivial, it is remarkable to see how positively youth respond to their parents when they are given many of these kinds of choices every day.

The second strategy in managing power struggles is in implementing the limited number of rigid rules at home. The well-used phrase, "Rules are made to be broken," is basically true. For example, people rarely drive the posted speed limit. If a posted speed limit is 60 miles per hour on a freeway, it is often the case that cars are traveling 65-70 miles per hour. What is the reason? It is human nature to resist rigid rules when people do not understand the reasons for a rule's inflexibility.

\section{Rules}

Rigid rules should be implemented primarily to assure health and safety. If children ride bikes, they must wear helmets. If people are traveling in a car, they need to wear seatbelts. Youth who pose a risk to others, or to the community, need to be closely supervised.

Specific strategies are important when implementing rules for health and safety:

- The specifics of each rule should be clearly described. Vague rules or rules that change are not as effective as those that are clear, repeated often, or even visually displayed.

- Why a rule is needed should be clear. Youth have long histories of resisting rules because, in part, they don't know why the rule exists. Caregivers should not assume that youth know the reasons for the rules.

- Rules should be stated by calm adults without elevated emotions, lectures, moralization, and long explanations.

- Rules should be stated positively by telling youth what is expected of them. It is common that children are told what not to do or what adults do not want them to do. Children tend to not hear the word not, but tend to hear only what follows the word do. For example, tell people not to think of an elephant and then ask them what they actually are thinking about ... most of the time they admit they are thinking of an elephant.

- Rewards should be clearly identified when youth follow the rules. Rewards can range from caregivers subtly acknowledging their good behavior, praising them, or giving them tangible rewards like money, special food, screen time, or later bedtimes.

- The consequences when rules are not followed should be clear. Restorative justice consequences are encouraged. Restorative justice means that when a rule is broken, the youth must do something to repair the impact of the 
broken rule. Consequences should be active as opposed to passive. Active consequences are when the youth has a task to repair the impact of the broken rule. Passive consequences are taking possessions away from youth or "grounding" youth. These are not as effective as active consequences.

- Rules should be reinforced $100 \%$ of the time by all the adults involved with the children. This is a problem when one parent is more apt to enforce rules, and the other parent might be more apt to be permissive and less emphatic about applying the rules. The same is true when parents enforce the rules but other adults (teachers, day care providers, extended family members, etc.) do not uphold the same standards.

\section{Open Environments}

Many children in out-of-home care programs have lived in birth or extended families in which members agreed to keep secrets, including child abuse and neglect, substance abuse, sexual abuse, criminal behavior, and domestic violence. There are compelling reasons for youth to keep secrets, including being afraid, not wanting to disclose unfavorable information about their families, and being loyal to their birth families. These are closed environments in which outside people are not allowed in and little inside information about the family is allowed out. CYS staff encourage open homes and relationships in which all the adults in any youth's life are committed to high levels of communication, collaboration, and cooperation. In fact, the adults' allegiance to openly and positively link with each other has to be as great as their allegiance to the youth they are supporting. Keeping secrets or restricting who can have contact with youth only replicates what happened to youth before.

A youth's multidisciplinary team can include the foster family, the birth and extended family, school staff, social workers, probation officers, and therapists. It is imperative that all of these people are committed to unified plans for that youth and the strategies to achieve those plans. Inevitably the adults on a youth's team are apt to be polarized unless there is a mutual commitment to communicate, collaborate, and cooperate with each other.

\section{Accountability}

Many youth understand that their escalated behavior can be viewed by adults as omnipotent. They have learned that they can make adults walk on eggshells around them by just the threat of a tantrum or defiance. Youth also learn that adults may be reluctant to hold them accountable for inappropriate behavior for fear of even more escalated behavior. Four things tend to happen when they act out: they get more therapy, they go to emergency respite, they get more medication, or they get placed into another home or facility.

It is important that youth be held accountable for negative behavior by the adults with whom they are having problems. Youth who are sent to respite, to an- 
other placement, or home from school when they have behavioral problems learn that adults are either not competent to address their escalated behavior or are not willing to address those problems.

The phrase "catch your child doing well" really does work! It is important to remember that accountability has the best impact when youth are recognized, acknowledged, and rewarded for positive behavior. Holding youth accountable is most effective when adults give positive attention to positive behavior that is the exception to the problem. For example, rewarding a youth for talking respectfully to others has a greater impact than punishing disrespectful interactions with adults. Rewards can range from tangible benefits like money, more screen time, later bedtimes, serving food they like, or prizes, to more subtle rewards like a smile, a pat on the back, or verbal acknowledgment that the adult noticed the positive behavior. Rewards are most effective when they are utilized frequently (many times per day) and immediately.

A sometimes underutilized reward includes activities youth can do with their foster parents. CYS staff and youth caregivers are encouraged to utilize their own interests and activities to engage youth and acknowledge positive behavior. Those interests and activities can be kicking a ball, playing catch, riding a bike, fixing something, cooking, gardening, learning a new skill together, going on rides in the car, and doing community service.

Establishing accountability strategies for antisocial behavior can be a bit more daunting. Restorative justice requires youth to repair the harm they have caused by their negative behavior and make it right to the person they harmed. Consequences are much less effective when delivered by someone other than the person with whom the youth had the problem. Restorative justice strategies convey to youth that their behavior adversely impacted someone. Identifying the effects of negative behavior is more effective than communicating to youth that they broke a rule. Restorative justice strategies increase responsibility and improved placement stability.

CYS staff and parents are encouraged to proactively identify appropriate consequences before problems arise. Trying to determine which consequence to use in the heat of escalated behavior is less effective.

Active consequences are better than passive consequences. With active consequences, the youth has to do something to make it right or to restore justice. With passive consequences adults take things away from youth or ground them for misbehavior. Taking things away from youth in out-of-home care only replicates what has already happened to them as they have pretty much had everything taken away from them already, including their families. Active consequences can include doing a job or doing something for the person who was negatively impacted by the youth's behavior. 
Consequences are most effective when they are utilized frequently for small behavioral transgressions. Youth learn by the frequency of the consequences, positive or negative, not by the intensity. CYS staff have observed that negative behavior decreases more quickly when multiple, small, immediate consequences are carried out each day. Conversely, negative behavior decreases much more slowly or not at all when parents try to impact behavior with larger, longer-term consequences . For example, having a youth wash one dish as a consequence for not taking their dishes to the sink after dinner is more effective than waiting for days to address the problem by having the youth wash everyone's dishes at a later time.

Consequences should also have a beginning and an end. Lecturing, moralizing, or preaching to the youth about why their negative behavior is not effective because youth rarely listen to those messages. Verbal messages serve only to convey the adults' frustration, which gives the youth negative power and control over the adults in their lives.

\section{Targeting Sequences of Behavior}

Youth do much better when adults intervene early in escalating behavior. Targeting sequences of behavior offers youth a sense of safety and skills to cope with emotional dysregulation.

Youth who have experienced trauma struggle with regulating their emotions, coping with stress, and moderating their escalating behaviors. In part, this is due to the high activity of the limbic system area of their brains. Caregivers and program staff are encouraged to intervene early by recognizing and addressing the antecedents of more escalated behavior. There is little evidence that ignoring escalated behavior will result in more stabilized behavior. When behavior goes past a one or two on the scale below, their behavior will go to a ten within the blink of an eye. Antecedents of escalating behavior can be as subtle as rolling of the eyes, a certain posture, a time of day, or even a location. For example, going into a store may be a predictor of escalating behavior if a youth is triggered by being in public. It is important that adults know the signals youth are giving to indicate that their behavior may be escalating on the ten-point scale below.

The best early intervention is to ask youth to "use their words" when the adult observes any predictor of escalating behavior. Encouraging youth to verbally express their feelings becomes an alternative to expressing their frustrations by acting out to get their needs met or to get adults to notice their dysregulation. 


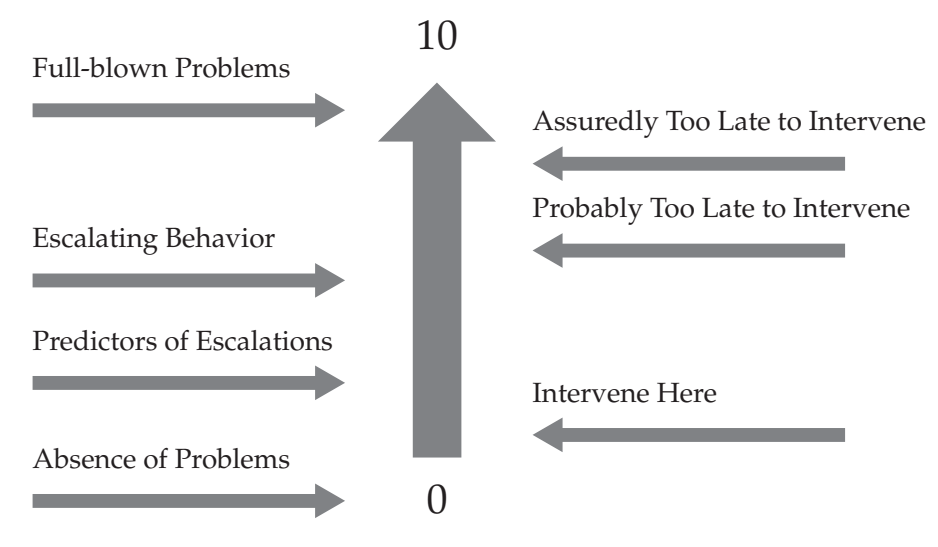

Figure 2

\section{Listening}

Youth who have experienced complex trauma have had few adults in their lives who have genuinely listened to them. Instead, they have experienced adults as order-givers who command youth to do what the adult thinks is best for the youth: "You need to go to therapy,"'“'You need to calm down,"'“'You need to stop behaving that way,"'’'You need to try harder at school."

CYS staff and caregivers have identified two styles of adult listening. The first style includes advice givers and correctors. Advice givers primarily focus on problems. They tend to tell youth what they did wrong, and they describe what behavior is more acceptable or appropriate. Ironically, advice givers believe youth are really listening and that their advice will be taken seriously. Correctors are more apt to lecture and preach. Youth tend to hear adult lectures as "blah, blah, blah."

The second style includes active listeners, who focus on feelings rather than behavior. Active listeners also encourage youth to keep talking. Active listeners understand that people, especially youth, listen more to what they themselves are saying than what someone else is telling them. Good listeners focus on strengths rather than problems. They also listen for what worked rather than what didn't work.

Probably the most important strategy in being a good listener is to be curious. Being curious and asking questions convey the message that the adult will truly listen to the youth's experience and how it made the youth feel. Having a curious listener also encourages youth to come up with their own solutions to challenges. CYS staff and caregivers are encouraged to utilize door opener phrases to encourage youth to keep talking. Door opener phrases include "How did that make you feel," "What are you feeling now," "Tell me more," "Hmm," "What else can you tell me about that," "Let's discuss it," " Go ahead, I'm listening," "What do you 
worry about," "Tell me the whole story," and so forth. Good listeners are also comfortable with silence.

Adults are also encouraged to regularly ask youth about their worries, understanding that youth in out-of-home care regularly worry about things that most people never have to think about. It can take a while before youth genuinely believe adults will listen and that adults really do care about how they feel. However, it doesn't take long for youth to learn that talking can help solve problems, especially when they have adults in their lives who will truly listen and accept what they have to say.

\section{Monitoring vs. Supervising}

Youth who come into the CYS therapeutic foster care program are often under orders that their caregivers must provide line-of-sight or twenty-four-hour, seven-days-per-week supervision. No one can provide that level of supervision. Even guards in maximum security prisons admit they cannot do that. Also, maximum security prisoners acknowledge that they know how to evade line-of-sight supervision in order to have contraband, sex, drugs, and alcohol. Youth will also do whatever they can to elude high levels of supervision because they perceive it as unnecessary and oppressive. They might run away, not come home from school, hide, and become deceptively sneaky to escape line-of-sight supervision. Inflexible supervision fosters youth dependence on adults and does little to support youth learning to make independent decisions.

However, line-of-sight supervision must be applied when health and safety is at risk. For example, youth who are registered sex offenders should only be around younger children while they are in sight and supervision of adults.

Monitoring, different from supervision, is defined by the following:

- Caregivers giving their permission for youth to be on their own in the community when with friends or when participating in social activities;

- Caregivers knowing where their youth are;

- Caregivers knowing what their youth are doing;

- Caregivers communicating with the parents of other youth involved;

- Caregivers establishing timelines for when their youth will check in or be home.

Monitoring offers youth opportunities to learn how to manage independence and autonomy. Almost all youth, especially adolescents, describe wanting freedom, choices, and opportunities to be on their own. Those opportunities can be offered when youth have demonstrated successes in asking for permission, when they are where they're supposed to be, when they check in on time, and when they come home on time. 


\section{Collaborating with Schools}

Stress at school shows up at home. Many traumatized youth have histories of behavioral challenges and academic deficits at school. This is largely due to that fact that many youth in foster care experience school as an environment in which they are not academically competitive are stigmatized as being different. There are valid reasons why youth who have experienced trauma are behind in school. They start kindergarten at a deficit because they may not have been read to nor have they had opportunities to participate in preschools. As they get older the academic gap between them and their peers often gets wider. It is important that caregivers and staff have compassion for how difficult it must be for youth to be at school in which they experience educational shortfalls and don't match up equally with their peers.

Success at home shows up at school. Children and adolescents become more successful at school, as measured by staying in school, improving grades, and having fewer behavior problems, when they feel safe, engaged with their families, and stable at home.

There is little evidence that youths' school successes are enhanced when their parents mandate remedial work at home in an effort to help the youth academically catch up. Caregivers should be expected to provide time and help with reasonable amounts of homework that is age and developmentally appropriate. Remedial schoolwork, mandated by their parents, deters youth from positively attaching to their parents. Youth see these caregivers as simply taskmasters whose primary mission is to make them succeed in school.

You may have heard the common belief that teachers spend about $80 \%$ of their time on $20 \%$ of the kids in their classrooms. Many of those $20 \%$ have experienced trauma and may even be in out-of-home care placements. Teachers will also state they have little training in working with youth who act out, who are emotionally dysregulated, and who are far behind academically. In an effort to support youth in out-of-home care, caregivers and staff are encouraged to help educators learn about trauma. For example, teachers experience most children to have high frustration tolerance. These students like being challenged and are interested in thought provoking assignments, whereas many of the youth who are in the CYS therapeutic foster care program struggle with low frustration tolerance. These youth frequently give up on trying to solve challenging tasks and school assignments. The Child Welfare Information Gateway (2004) identifies low frustration tolerance as a risk factor for child abuse and neglect.

It is important teachers and school administrators are helped to understand that expelling or suspending youth from school for behavioral problems is not usually effective. As stated above, children should be held accountable by the adults with whom youth have a behavior problem. Suspensions and expulsions give children the message that the school staff members are either unwilling or not capable of dealing with youth. Many youth in out-of-home care programs would rather be 
at home than at school, even if there are consequences at home. Having caregivers take on the role of punishers for a youth's problems at school deters the primary goal of foster parents. Staff at CYC want foster parents to focus on engagement, warmth, and compassion to enhance stability rather than be disciplinarians for the youth's behavior or academic problems at school.

However, a positive home-school link is important to overall academic success. The home-school link can help youth's teachers understand what works with particular children. It also includes foster parents knowing about the Individual Education Plan (IEP) process and how to utilize the IEP to assure their children will get the help or accommodations they need to succeed at school. A homeschool link conveys to youth that the adults in their lives are positively communicating, collaborating, and cooperating with each other in youth's best interests.

\section{Enhancing Prosocial Activities, Prosocial Peer Relationships, and Prosocial Adult Relationships}

CYS has increased its resources for youth, families, and staff to participate in prosocial activities. Some resources were even rededicated from traditional supports like individual therapy and tutoring so youth could learn new skills, be active, and have fun with the significant adults in their lives. Sports, music, arts, dance, climbing, cooking, knitting, volunteering in the community, rafting, skiing, snowboarding, sewing, fishing, gardening, and especially aerobic exercise are examples of the CYS prosocial activities. Improved CFAR scores and improved behavior at CYS seem to be correlated to youth engagement in prosocial activities. Many youth who are referred to the CYS therapeutic foster care program have had few opportunities to participate in or be successful in prosocial activities. Caregivers are encouraged to utilize their own interests, activities, and hobbies to enhance engagement and to keep youth active. Prosocial activities have to be individualized based upon the chronological age, emotional age, and self-regulation of the youth. Certainly not every youth is ready to play competitive sports, but most youth can go to a public pool to swim or go on a walk or ride a bike with someone in their family.

Physical exercise with and for youth is emphasized at CYS. According to research by Medina (2014), "Physically fit children identify visual stimulus much faster than sedentary ones. They appear to concentrate better. Brain activation studies show that children and adolescents who are fit allocate more cognitive resources to a task and do so for longer periods of time."

One of the biggest contributors to a youth's behavior are their friends. Youth who come into CYS's therapeutic foster care program often describe themselves as having friends. However, when asked if their friends make their lives better or worse, they frequently acknowledge incidents where they have gotten into trouble with their friends. It is common for people to be attracted to others who look like them, share the same interests, think like them, and behave like them. Youth who have experienced trauma are no different. They tend to gravitate to peers who have 
similar behavior, language, and demeanor. Caregivers and staff should monitor the friends of their youth. It is even more important for caregivers to develop strategies that will encourage young people to engage with friends who are positive influences on their lives. Engaging youth in prosocial activities is one way of helping foster youth meet prosocial peers. Preliminary research at CYS shows a direct correlation between increased prosocial activities and decreased critical incidents such as, running away, being aggressive, and having behavior problems at school.

Caregivers and staff should also be encouraging youths' relationships with adults who will improve their lives. Permanency for youth is defined in two ways. One definition is family on whom youth can rely for support throughout their lives. The second definition is when youth are connected with an adult who will follow that youth through life. Prosocial adults can be coaches, neighbors, extended family, educators, friends, Big Brothers, Big Sisters, and clergy. It is important that youth are positioned to develop relationships with those prosocial adults.

\section{Conclusion}

People who have a job can tell one what they do. People who have a profession can tell one why they do it. Any profession requires ongoing learning, training, and practice. Doctors, teachers, lawyers, and athletes acknowledge they will never know everything about their work. All professionals have to participate in continuing education and training.

Positive outcomes at CYS are, in large part, due to caregivers and staff professionally embracing this second set of parenting skills. Caregivers also understand that their practice is doing the same things over and over, sometimes hundreds of times. Rarely does one intervention, discussion, or strategy result in a significant change in behavior or functioning.

Yet, these skills can support youths' success in many of domains of their lives. Placement stability at CYS is over $90 \%$ as a result of parents embracing and practicing these skills. The CYS foster family retention rate also increased when parents felt trained and supported in implementing these skills. Youth who come into CYS homes recognize that their caregivers are experienced, competent, and confident.

CYS caregivers respect youths' birth and extended families. They work hard to engage the youths' families, when appropriate, with the knowledge that their youths' allegiance and loyalty to their birth families is unshakeable.

Staff and foster parent retention is also an important factor in placement stability. Youth who come into care at CYS know that the adults with whom they are working have experience with youth who are similar to themselves. CYS's therapeutic foster care program staff retention rate for the last 10 years is 5.3 years, while CYS current foster family retention rate is 5.5 years.

Much is written about how vulnerable caregivers are to vicarious or secondary distress that comes with working with youth who have experienced trauma. Much is also written about ways caregivers and staff should practice self-care to 
deter the impact of vicarious trauma. CYS staff encourage caregivers to develop a support system that is natural and community based that includes friends, neighbors, clergy, and work colleagues. These community supports are as important as professionally based advocates like staff, case managers, and therapists.

CYS encourages parents to maintain a clear sense of their own adult identity. Caregivers are supported in continuing with their own hobbies, interests, and activities outside of parenting responsibilities. CYS staff utilize financial resources to support caregivers' interests and activities and to provide proactive respite care so adults can emotionally refuel.

CYS staff believe that resilience is defined as one's ability to meet challenges, survive, and do well despite adversity. Resilience is the capacity to bounce back from a history of trauma. Youth can learn resilience by feeling safe and by being engaged with adults who are self-regulated. Resilience is also enhanced when youth live in stable placements without fear of having to continually move.

CYS staff collaborate with Native American tribes in the Pacific Northwest, who advance the importance of the "Circle of Courage." Youth will do well when they sense their own competence in the domains of the "Circle of Courage" (Brendtro, Brokenleg, \& Van Bockern, 2005).

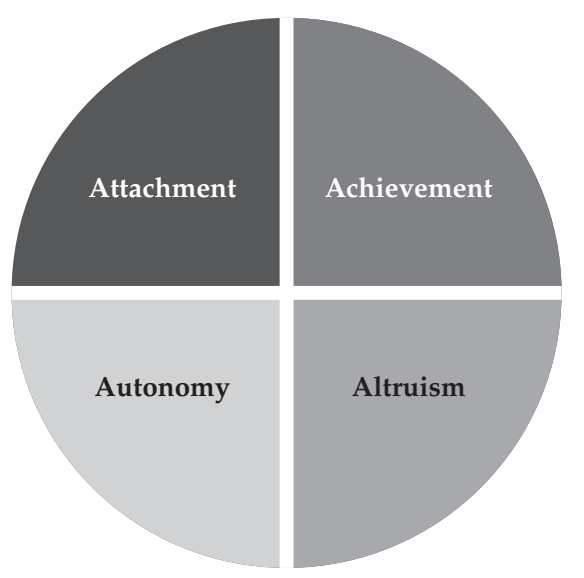

Figure 3

The goals at CYS are that every youth will feel bonded and safe, be able to master tasks and learn helpful skills in life, be independent and utilize good judgment, and give back to their communities. In other words: attachment, achievement, autonomy, and altruism. 


\section{References}

Amen, Daniel G. (1998). Change Your Brain Change Your Life-A Breakthrough Program for Conquering Anxiety, Depression, Obsessiveness, Anger and Impulsiveness. New York, NY: Three Rivers Press.

Brendtro, L., Brokenleg, M., \& Van Bockern, S. (2005). The Circle of Courage and Positive Psychology. Reclaiming Youth International.

Child Welfare Information Gateway. (2004). Risk and Protective Factors for Child Abuse and Neglect. Washington, DC.

Gray, D. (2007). Nurturing Adoptions: Creating Resilience After Neglect and Trauma. Indianapolis, IN: Perspectives Press, Inc.

Henggeler, S. W., Schoenwald, S. K., Borduin, C. M., \& Cunningham, P. B. (2009). Multisystemic Therapy for Antisocial Behavior in Children and Adolescents. Second Edition. New York, NY: Guilford Press.

Hieger, Jessica. (2012). Post Traumatic Stress Disorder and Children in Foster Care. New York, NY: Children's Bureau.

Lobnghi, D. (2012). Prevalence of Adverse Childhood Experiences Among Young Adults in Thurston County: A Fact Sheet. Washington State Family Policy Council.

Medina, J. (2014). Brain Rules 12 Principles for Surviving and Thriving at Work, Home and School. Seattle, WA: Pear Press.

Rollnick, S., Miller, W., \& Butler, C. (2008). Motivational Interviewing in Health Care: Helping Patients Change Behavior. New York, NY: Guilford Press.

Van Dernoot, L. (2009). Trauma Stewardship An Everyday Guide to Caring for Self While Caring for Others. San Francisco, CA: Berrett-Koehler Publishers.

Whitlock, J., \& Purington, M. h. (2013). Cornell Research Program on Self Injury and Recovery. Ithaca, NY: Cornell University. 